\section{UK information technology research programme criticized}

\section{London}

BRITAIN's national programme of research in advanced information technology has largely failed to live up to its original expectations, according to the independent scrutineers of public spending, the National Audit Office (NAO). The programme has been hampered by administrative weaknesses and shortages of suitably qualified personnel and will spend some $£ 60$ million more than initially envisaged, the NAO says in a report* published last week.

In an attempt to increase Britain's competitiveness in information technology in world markets, the government launched in 1983 the Alvey programme, with $£ 200$ million of public money, from the Department of Trade and Industry (DTI), the Science and Engineering Research Council and the Ministry of Defence, and $£ 150$ million from private industry. The administrative difficulties highlighted by the NAO have been acknowledged by the Alvey directorate. They arose chiefly because of the problems in coordinating three government departments with inadequate central administration. The directorate, based in the DTI, was severely understaffed so that highly skilled technical personnel had to spend time typing and filing.

The NAO points out that the directorate did not initially establish central management and financial information systems, making the provision of programme data more labour intensive and less comprehensive and reliable "than it should have been for a complex programme of this sort". The NAO acknowledges that in spite of the problems of administration, "which may have been partly caused by a lack of resources", the programme did draw up detailed strategies within 14 months and got 300 projects under way by March last year.

One of Alvey's chief objectives was to foster collaborations between industry, academics and research organizations. In this it succeeded to a largely commendable degree, the report says. But it qualifies its praise by noting that difficulties in establishing collaborative arrangements caused "significant delays" and withdrawals from the programme, and that project managers believed that the Alvey directorate could have helped more.

Despite the directorate's view that evidence of exploitable results emerging from nearly half of the 200 industrial projects by the middle of last year was "highly encouraging", the NAO says that the rate of exploitation was lower than originally foreseen. In particular, the software engineering programme, which had been seen as having the greatest potential for rapid exploitation, had yielded no marketable products by mid- 1987 .

On the programme's finances, the NAO says that the Alvey board decided to spend some $£ 35$ million more on academic research and on programme administration and infrastructure than had been originally intended. So, total expenditure on Alvey research is likely to be around $£ 60$ million less than first thought.

Throughout the programme, skills shortages have hampered progress, particularly in the area of artificial intelligence, the report says. In more than half of the 42 projects studied by the NAO, manpower shortages were reported, resulting in delays, needs for extensions,

\section{London}

THE rock-carvings of the Indus valley, a unique anthropological tr easure spanning more than four millennia, are under grave threat of destruction according to Professor Karl Jettmar of Heidelberg University, addressing a conference on the religions of central Asia in London last week. Yet the sheer abundance of the carvings (more than 20,000, including more than 2,000 inscriptions, extending some $70 \mathrm{~km}$ along the Indus valley), make rescue impractical. The best hope, Jettmar said, is for archaeologists and anthropologists to make a detailed record of the carvings before they are lost.

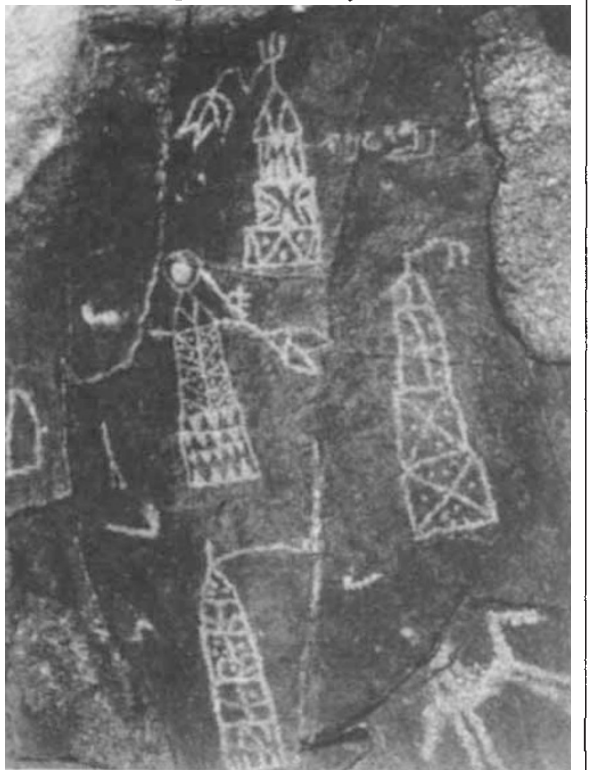

Carving of stupas (interpreted as demons), traditional animal figure and inscription in Sanskrit alphabet. withdrawal of partners and the use of foreign experts. The original Alvey committee recognized the problems of skills shortages and recommended a specific role for the Alvey directorate to monitor manpower needs for the programme and to introduce action necessary to meet them. Such a role was not conferred.

Those closely associated with Alvey see the NAO report as concentrating too heavily on the problems encountered while failing to give sufficient credit for the part Alvey has played in promoting collaboration, particularly between companies whose researchers would probably not have otherwise had formal contact.

The NAO report will go before the House of Commons public accounts committee next month, when the agencies involved in the programme will be asked to comment.

Simon Hadlington

Department of Trade and Industry: The Alvey Programme for Advanced Information Technology. HMSO, £5.20.

\title{
Indus Valley rock carvings under threat from road-building plans
}

The Indus Valley is the shortest natural route between Central Asia and what is now northern Pakistan. The carvings, preserved on account of the very dry climate, in the lee of the Karakoram mountains, reveal the shifting pattern of cultures and beliefs, making them what Jettmar called "the visiting card of history."

According to Jettmar, the first threat to the carvings was the decision of the Pakistan government to build a modern highway from Islamabad along the Indus valley to the Khungerab pass. Although the highway itself did relatively little damage, providing easier access when foreign archaeologists were allowed back into the area in 1979, the road seems to have inspired local people to build European-style houses, chopping up the nearest available rock for building blocks. Moreover, the new, fundamentalist mullahs, no longer prepared to accept the old folk-beliefs of the area, have convinced the locals that there was no supernatural danger in destroying the carvings.

An even greater threat, however, comes from the Tarbela reservoir, near Abbottabad. Although far downstream from the carvings, the reservoir is filling up fast with Indus silt and is likely to become useless in a few decades, possibly before it has paid for itself. And the planned relief reservoir at Basha will be only $30 \mathrm{~km}$ downstream from the richest area of carvings around Chilas village and will create a $40 \mathrm{~km}$ long lake drowning many of these carvings. The need to raise the level of the Karakoram highway by $200 \mathrm{~m}$ will also, Jettmar says, imperil many carvings not actually threatened with submersion. 